\title{
Mechanistic Molecular Motion of Transition-Metal Mediated $\beta$-Hydride Transfer: Quasiclassical Trajectories Reveal Dynamically Ballistic, Dynamically Unrelaxed, Two Step, and Concerted Mechanisms
}

\author{
Josh Wheeler ${ }^{\text {a }}$, Ryan Carlsen ${ }^{\text {a }}$, and Daniel H. Ess ${ }^{* a}$ \\ aDepartment of Chemistry and Biochemistry, Brigham Young University, Provo, Utah 84602. \\ *E-mail: dhe@chem.byu.edu
}

\begin{abstract}
The transfer of a $\beta$-hydrogen from a metal-alkyl group to ethylene is a fundamental organometallic transformation. Previously proposed mechanisms for this transformation involve either a two-step $\beta$-hydrogen elimination and migratory insertion sequence with a metal hydride intermediate or a one-step concerted pathway. Here, we report density functional theory (DFT) quasiclassical direct dynamics trajectories that reveal new dynamical mechanisms for the $\beta$-hydrogen transfer of $\left[\mathrm{Cp}^{*} \mathrm{Rh}{ }^{\text {III}}(\mathrm{Et}) \text { (ethylene) }\right]^{+}$. Despite the DFT energy landscape showing a two-step mechanism with a Rh-H intermediate, quasiclassical trajectories commencing from the $\beta$-hydrogen elimination transition state revealed complete dynamical skipping of this intermediate. The skipping occurred either extremely fast (typically $<100$ femtoseconds (fs)) through a dynamically ballistic mechanism or slower through a dynamically unrelaxed mechanism. Consistent with trajectories begun at the transition state, all trajectories initiated at the $\mathrm{Rh}-\mathrm{H}$ intermediate show continuation along the reaction coordinate. All of these trajectory outcomes are consistent with the $\mathrm{Rh}-\mathrm{H}$ intermediate $<1 \mathrm{kcal} / \mathrm{mol}$ stabilized relative to the $\beta$-hydrogen elimination and migratory insertion transition states. For Co, which on the energy landscape is a one-step concerted mechanism, trajectories showed extremely fast traversing of the transition-state zone ( $<50 \mathrm{fs})$, and this concerted mechanism is dynamically different than the $\mathrm{Rh}$ ballistic mechanism. In contrast to Rh, for Ir, in addition to dynamically ballistic and unrelaxed mechanisms, trajectories also stopped at the $\mathrm{Ir}-\mathrm{H}$ intermediate. This is consistent with an $\mathrm{Ir}-\mathrm{H}$ intermediate that is stabilized by $\sim 3 \mathrm{kcal} / \mathrm{mol}$ relative to the $\beta$-hydrogen elimination and migratory insertion transition states. Overall, comparison of $\mathrm{Rh}$ to $\mathrm{Co}$ and Ir provides understanding of the relationship between the energy surface shape and resulting dynamical mechanisms of an organometallic transformation.

\section{Introduction}

The transfer of a $\beta$-hydrogen from a metal-alkyl group to ethylene is a fundamental organometallic transformation. ${ }^{1}$ The classically proposed mechanism for this process involves the twostep sequence of $\beta$-hydrogen elimination that results in a metal-hydride intermediate followed by migratory insertion (Scheme 1a). Density functional theory (DFT) calculations have also identified the alternative direct one-step transfer pathway where the metal-hydride intermediate is not formed, and the transfer occurs in a concerted transition state. ${ }^{2,3}$ Experiments and DFT calculations have demonstrated that an agostic $\mathrm{C}$-H-to-metal interaction likely occurs prior to and after $\beta$-hydrogen transfer..$^{4-8}$
\end{abstract}



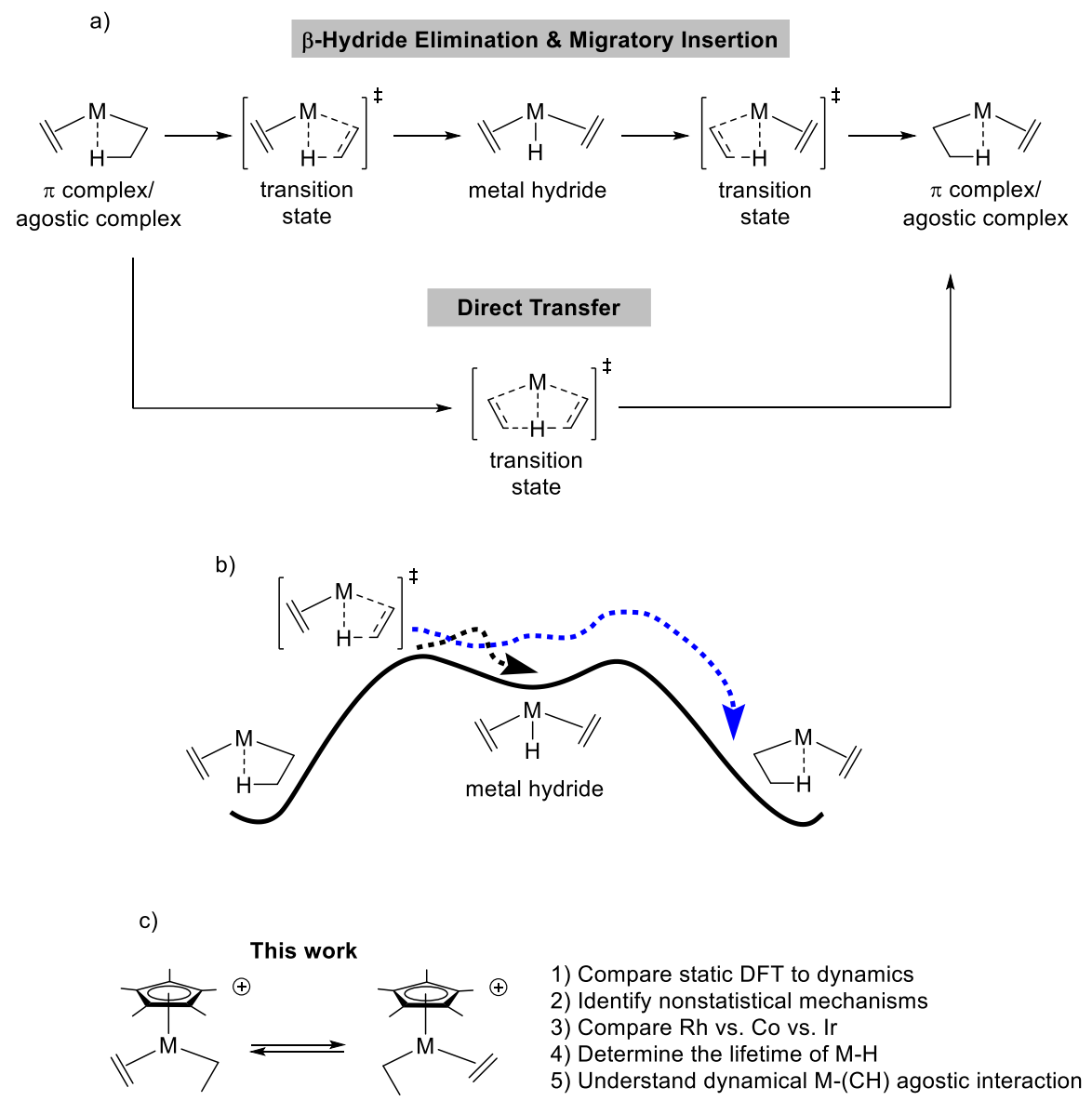

$\mathrm{M}=\mathrm{Rh}, \mathrm{Ir}$, Co

Scheme 1. a) Outline of two-step and one-step $\beta$-hydrogen-to-ethylene transfer reaction mechanisms. b) Qualitative energy landscape for the two-step sequence of $\beta$-hydrogen elimination with a metal-hydride intermediate followed by migratory insertion. The black dashed arrow represents a possible statistical trajectory that leads from the $\beta$-hydrogen elimination transition state to the metal-hydride intermediate. The blue dashed arrow represents the possible nonstatistical dynamical trajectory outcome where the metal-hydride intermediate is skipped. c) This work uses quasiclassical direct dynamics trajectories to determine the dynamical mechanisms for $\beta$-hydrogen transfer of [Cp*M"'(Et)(ethylene) $]^{+}$.

The two-step mechanism outlined in Scheme 1a is based mainly on DFT energy landscapes that assume statistical behaviour of the metal-hydride intermediate. This statistical mechanistic assumption is intriguing because we previously reported that for the Ir-Me $\sigma$-bond metathesis reaction between $\left[\mathrm{Cp} *\left(\mathrm{PMe}_{3}\right) \mathrm{Ir}^{\prime \prime \prime}\left(\mathrm{CH}_{3}\right)\right]^{+}$and methane and benzene, which also has a two-step DFT energy landscape with an intervening Ir-H intermediate, quasiclassical direct dynamics trajectories revealed that $15-20 \%$ of trajectories skip the $\mathrm{Ir}-\mathrm{H}$ intermediate in a nonstatistical, dynamically concerted mechanism. ${ }^{9}$ Therefore, we were interested in the possibility that for $\beta$-hydrogen-to-ethylene transfer quasiclassical trajectories might reveal new nonstatistical ${ }^{10,11}$ or non-IRC dynamical reaction mechanisms that are different from either of the classical two-step or one-step mechanisms shown in Scheme $1 a .{ }^{12-16}$ We also wanted to determine how the transition-metal centre influences the shape of energy surface landscape and the resulting trajectory outcomes. Additionally, because the ground-state agostic interaction has been proposed to be important in $\beta$-hydrogen transfer, we wanted to explore the dynamics of this intermediate after $\beta$-hydrogen transfer. 
We chose to focus our direct dynamics study on the $\beta$-hydrogen transfer reactions for $\left[\mathrm{Cp}^{*} \mathrm{Rh}^{\prime \prime \prime}(\mathrm{Et})(\text { ethylene) }]^{+}\right.$and $\left[\mathrm{Cp}^{*} \mathrm{Co} \mathrm{O}^{\text {III }}(\mathrm{Et})(\text { ethylene) }]^{+}\right.$for several reasons. 1) Experimentally, the $\beta$ hydrogen transfer reaction has been reported for [C $\mathrm{C}^{*} \mathrm{Rh}^{\mathrm{II}}(\mathrm{Et})$ (ethylene) $]^{+}$in solution phase ${ }^{4}$ and in the gas phase using FT-ICR mass spectrometry. ${ }^{5}$ In the gas phase study, it was shown that [Cp* Rh"I $\left.(\mathrm{Et})\right]^{+}$ reacts with ethylene to give addition to the metal centre, rapid intermolecular hydrogen exchange with $\mathrm{C}_{2} \mathrm{D}_{4}$, and ligand substitution. 2) Previous DFT calculations showed that this Rh reaction has a two-step $\beta$-hydrogen transfer energy landscape similar to the surface shown in Scheme 1b. 3) The [Cp*Co"I(Et)(ethylene)] $]^{+}$reaction has also been experimentally reported, and the dynamics of the agostic interaction were measured, although at a slow NMR time scale compared to reaction dynamics. 4) In contrast to Rh, previous DFT calculations showed that this Co reaction has a one-step concerted energy landscape. 5) We also chose to compare the Rh and Co reactions with the analogous $\left[C p^{*} I^{\prime \prime \prime}(E t)(\text { ethylene }]^{+} \beta\right.$-hydrogen transfer reaction because while the DFT energy landscape shows two steps, the $\mathrm{Ir}-\mathrm{H}$ intermediate is more stable than the $\mathrm{Rh}-\mathrm{H}$ intermediate.

Based on quasiclassical direct dynamics trajectories, this work demonstrates that for the $\beta$ hydrogen transfer reaction of [Cp* Rh"'(Et)(ethylene) $]^{+}$, despite the DFT energy landscape showing a twostep mechanism, all non-recrossing trajectories resulted in complete skipping of the Rh-H intermediate. The skipping either occurred extremely fast through a dynamically ballistic mechanism or slightly slower through a dynamically unrelaxed mechanism. For Co that has a one-step energy landscape, trajectories showed extremely fast traversing of the transition-state zone $(<50 \mathrm{fs})$, which provides a timing benchmark for a concerted $\beta$-hydrogen mechanism. For both $\mathrm{Rh}$ and Co reactions, after $\beta$-hydrogen transfer the relatively fast dynamics of the agostic $\mathrm{C}$-H-to-metal interaction was observed. For Ir, in addition to dynamically ballistic and unrelaxed skipping of the Ir-H intermediate, trajectories also stopped at the Ir-H intermediate. Overall, trajectories for the Rh, Co, and Ir reactions provide an energy surface shape to dynamical mechanism relationship for this $\beta$-hydrogen transfer organometallic transformation.

\section{Methodology}

DFT structures for energy landscapes were optimized in Gaussian $16^{17}$ with the M06 functional using the 6-31G** [LANL2DZ for Ir, Rh, and Co] and Def2-TZVPD basis sets. ${ }^{18}$ The 6-31G** [LANL2DZ] and Def2-TZVPD basis sets gave very similar structures and relative energies. All structures were optimized with a very fine integration grid and with very tight convergence criteria. Thermochemical corrections for enthalpies and Gibbs free energies were applied using the standard rigid rotor-harmonic oscillator approximation. Use of the quasi-harmonic oscillator approximation changed energies by $<0.1 \mathrm{kcal} / \mathrm{mol}$. Final Gibbs energies in Figure 1 are M06/Def2-TZVPD//M06/6-31G**[LANL2DZ].

Trajectory calculations were carried out in Gaussian $16^{17}$ with M06/6-31G** [LANL2DZ] with an ultrafine integration grid. Trajectories with our program DynSuite gave very similar results. ${ }^{9}$ Quasiclassical trajectories that included zero-point energy (ZPE) were initialized and propagated from the $\beta$-hydrogen elimination transition-state structure for $\mathrm{Rh}$ and $\mathrm{Ir}$, and from the direct, one-step transition-state structure for Co. Initialization of trajectories was done using local mode and thermal sampling at $298 \mathrm{~K}$. Trajectories were propagated in mass-weighted Cartesian velocities with an approximate average step of $0.75 \mathrm{fs}$, which we previously showed for organometallic reactions is a short enough time step to give results identical to time steps as small as $0.25 \mathrm{fs} .{ }^{19}$ Forward trajectories were launched so that the transition-state vibrational mode was followed in the direction for increasing the length of the breaking ethyl group $\mathrm{C}-\mathrm{H}$ bond. Reverse trajectories followed the direction of decreasing this $\mathrm{C}-\mathrm{H}$ bond length. Both the gradient and Hessian were updated at each time step. Importantly, we previously showed that the average potential energy drift over the course of the trajectory for organometallic reaction is significantly less than $0.1 \mathrm{kcal} / \mathrm{mol}$. 
Results and Discussion

Static DFT energy landscapes

$\left[\mathrm{Cp}^{*} \mathrm{M}^{\prime \prime \prime}(\mathrm{Et}) \text { (ethylene) }\right]^{+}$type complexes are important to understand because they represent fundamental intermediates in molecular catalysis of ethylene polymerization. To understand the intramolecular equilibrium between ethyl and ethylene groups, Brookhart used variable temperature ${ }^{1} \mathrm{H}$ and ${ }^{13} \mathrm{C}$ NMR to track $\beta$-hydrogen transfer in [Cp* Rh"'(Et)(ethylene) $]^{+}$(1Rh, Figure 1a) and [Cp*Co"I'(Et)(ethylene)] $]^{+}(\mathbf{1 C o}) .{ }^{4} \mathbf{1} \mathbf{R h}$ was generated by protonation of $\mathrm{Cp}^{*} \mathrm{Rh}^{\prime}\left(\right.$ ethylene) ${ }_{2}$ with $\left[\mathrm{H}^{+}\right]\left[\mathrm{BF}_{4}{ }^{-}\right.$ ][Me $\mathrm{Me}_{2} \mathrm{O}$. NMR studies at approximately $-80^{\circ} \mathrm{C}$ showed very rapid $\left(\mathrm{k}=\sim 9 \times 10^{6} \mathrm{~s}^{-1}\right) \beta$-hydrogen transfer from the ethyl group in $\mathbf{1 R h}$ to the coordinated ethylene group. While $\beta$-hydrogen transfer was the lowest energy process observed by ${ }^{1} \mathrm{H} N \mathrm{NMR}$, at higher temperatures ethyl group rotation was also observed, which interchanges the $\mathrm{C}-\mathrm{H}$ bonds with an agostic interaction with the Rh metal center. However, it was unknown if this rotation was independent or coupled with $\beta$-hydrogen transfer. At even higher temperatures $\left(-20^{\circ} \mathrm{C}\right)$ a third process was observed where there was a complete averaging of nine ${ }^{1} \mathrm{H}$ NMR signals corresponding to the ethyl and ethylene groups. It was proposed that this process could be the result of either ethylene group rotation or Rh center inversion. While the NMR studies were critical to identify pathways associated with $\beta$-hydrogen transfer, these studies did not determine if the transfer occurs through a one-step or two-step mechanism, and Brookhart proposed that the Rh- $\mathrm{H}$ $\mathbf{2} \mathbf{R h}$ could either be an intermediate or a transition state. ${ }^{4}$ 


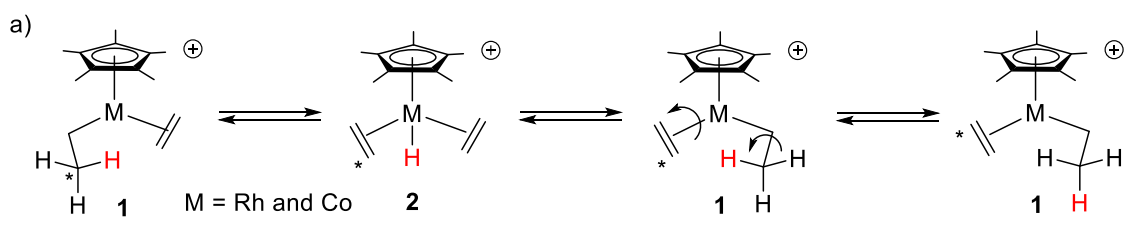

b)

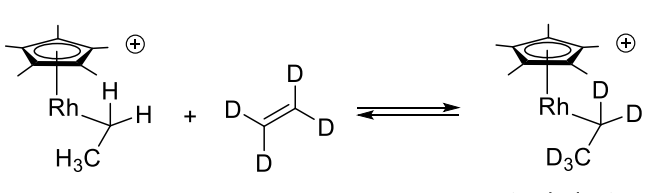

up to $d_{5}$ isotopolog
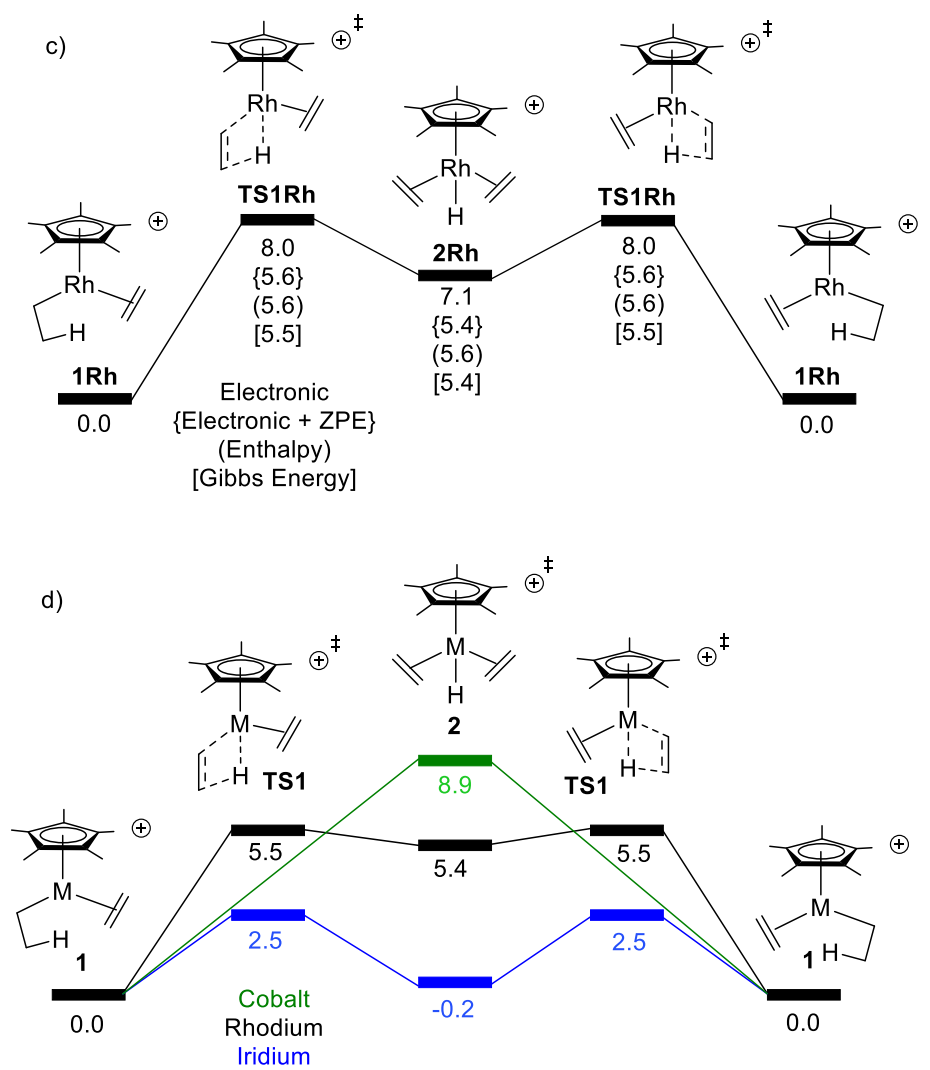

Figure 1. a) Outline of $\beta$-hydrogen transfer reaction mechanism proposed by Brookhart based on variable temperature NMR studies. ${ }^{4}$ b) Outline of experimental gas-phase hydrogen/deuterium exchange for the reaction of [Cp* Rh"I $(E t)]^{+}$with $\mathrm{C}_{2} \mathrm{D}_{4}{ }^{5} \mathrm{c}$ ) M06/6-31G**[LANL2DZ] DFT energy landscape for $\beta$-hydrogen transfer for 1Rh. d) Comparison of M06/6-31G**[LANL2DZ] energy landscapes for intramolecular $\beta$-hydrogen transfer for [Cp*M(Et) $\left.\left(\mathrm{C}_{2} \mathrm{H}_{4}\right)\right]^{+}$where $\mathrm{M}=\mathrm{Rh}, \mathrm{Co}$, and Ir. Energy values in $\mathrm{kcal} / \mathrm{mol}$.

Consistent with Brookhart's solution-phase NMR studies of $\mathbf{1 R h},{ }^{4}$ Tilset reported FT-ICR mass spectrometer gas-phase studies for the reaction of $\left[\mathrm{Cp}^{*} \mathrm{Rh}{ }^{\prime \prime \prime}(\mathrm{Et})\right]^{+}$with $\mathrm{C}_{2} \mathrm{D}_{4}{ }^{5}$ On the second time scale, this reaction showed the rapid appearance of a close-to-statistical build-up of [Cp* $\left.\mathrm{Rh}^{\prime \prime \prime}(\mathrm{Et})\right]^{+}$complexes with $\mathrm{m} / \mathrm{z}$ of 268-272 that correspond to deuterium isotopologs (Figure $1 \mathrm{~b}$ ). With guidance from BP86 DFT calculations, to explain the formation of statistical isotopologs of [Cp*Rh"'(Et)] $]^{+}$Tilset proposed a gas-phase mechanism involving $\mathrm{C}_{2} \mathrm{D}_{4}$ coordination, ${ }^{5} \beta$-hydrogen elimination, migratory insertion, and 
ethylene dissociation. Tilset's DFT calculations also demonstrated that pathways other than those proceeding through $\mathbf{1 R h}$ and $\mathbf{2} \mathbf{R h}$, such as vinyl $\mathrm{C}-\mathrm{H}$ bond activation are significantly higher in energy. ${ }^{5}$

Brookhart also used NMR studies to examine the hydrogen and carbon scrambling processes in 1Co. ${ }^{4}$ The ethyl group to ethylene $\beta$-hydrogen transfer equilibrium was measured to have a Gibbs free energy barrier a few $\mathrm{kcal} / \mathrm{mo}$ higher than the barrier for $\mathbf{1 R h}$. In this reaction, it was also proposed that either the $\mathrm{Co}-\mathrm{H}$ was a transition state or intermediate during $\beta$-hydrogen transfer.

Computationally, Hall previously examined the $\beta$-hydrogen transfer of $\mathbf{1 R h}$ with ab initio MP2 calculations. ${ }^{2}$ These calculations established that the transfer process occurs through a mechanism where on the energy landscape the $\mathrm{Rh}-\mathrm{H} \mathbf{2} \mathbf{R h}$ is an intermediate rather than a transition-state structure. Similar to Hall, ${ }^{2}$ the Tilset BP86 DFT calculations also showed that $\beta$-hydrogen transfer in $\mathbf{1 R h}$ occurs via a two-step energy landscape with the intervening Rh-H intermediate. ${ }^{5}$ The MP2 barrier from $1 \mathbf{R h}$ to $\mathbf{2 R h}$ was calculated to be $5.3 \mathrm{kcal} / \mathrm{mol}$ with the intermediate $\mathbf{2} \mathbf{R h} 3.4 \mathrm{kcal} / \mathrm{mol}$ higher than $\mathbf{1} \mathbf{R h}$. An approximate transition state with a barrier of $6.5 \mathrm{kcal} / \mathrm{mol}$ was reported for rotation between $\mathrm{C}-\mathrm{H}$ bonds forming an agostic interaction (i.e. rotation of the methyl group) with the Rh metal center. The complete loss of the agostic interaction was estimated to be $>14 \mathrm{kcal} / \mathrm{mol}$. This large energy for detachment of the $\mathrm{C}-\mathrm{H}$ bond from the $\mathrm{Rh}$ metal center suggested that ethylene rotation, which was computed to have an approximate barrier of $10 \mathrm{kcal} / \mathrm{mol}$, rather than Rh center inversion is responsible for the average signal of all nine hydrogens reported by Brookhart. ${ }^{4} \mathrm{Hall}$ also reported a $7.2 \mathrm{kcal} / \mathrm{mol} \mathrm{MP} 2$ barrier for $\beta$ hydrogen elimination of $\mathbf{1 C o}$ to $\mathbf{2} \mathrm{Co}^{2}{ }^{2}$

Because the Brookhart and Tilset studies established the $\beta$-hydrogen transfer reaction in solution and gas-phase, ${ }^{4,5}$ and ab initio and DFT methods showed a two-step mechanism with an intervening Rh-H intermediate, we began by computing 1Rh, 2Rh, and TS1Rh using M06 DFT. These and all other structures can be found in the ESI. Also, see the ESI for MN15 and $\omega$ B97X-D values, which gave similar energies. Overall, our M06 energies and structures are similar to Hall's and Tilset's previous structures (Figure $1 \mathrm{~b}$ ). ${ }^{2,5}$ Relative to $\mathbf{1 R h}$, our estimate for the $\Delta G^{\ddagger}$ for TS1Rh is $5.5 \mathrm{kcal} / \mathrm{mol}$ and $\mathbf{2 R h}$ is $5.4 \mathrm{kcal} / \mathrm{mol}$. At $-80^{\circ} \mathrm{C}$ these structures have nearly identical Gibbs energies. Our gas phase Gibbs barrier estimate is slightly higher than the experimental solution phase value of $\leq 3.7 \mathrm{kcal} / \mathrm{mol}$ reported by Brookhart. ${ }^{4}$ Very similar to Tilset's BP86 energy surface, ${ }^{5} \mathbf{2 R h}$ is $<1 \mathrm{kcal} / \mathrm{mol}$ lower in energy than TS1Rh. Again, this flat landscape suggests that there is the possibility of dynamically skipping the $\mathrm{Rh}-\mathrm{H}$ intermediate. 

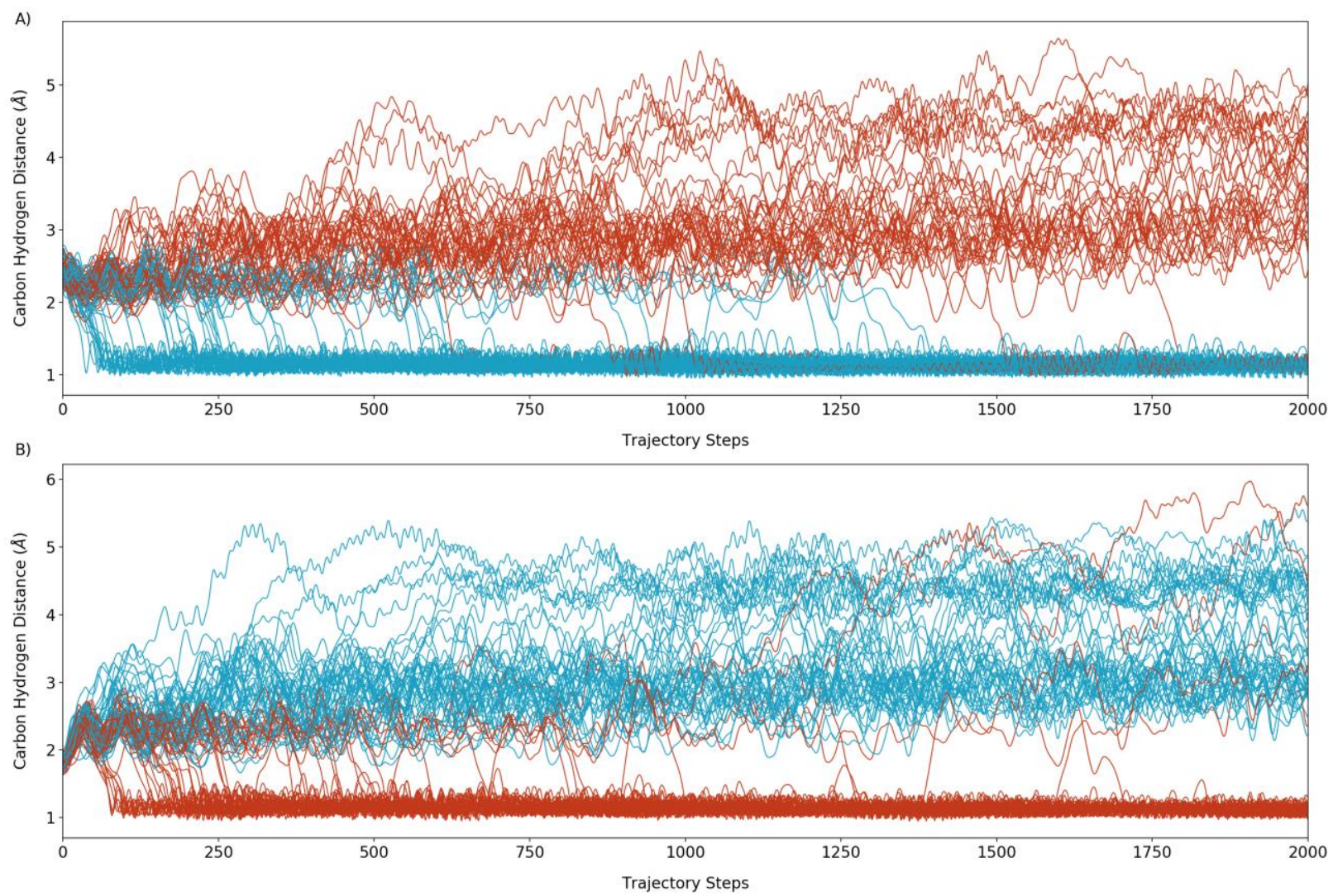

Figure 2. a) Plot of forming $\mathrm{C}-\mathrm{H}$ bond distance $(\AA)$ versus trajectory steps beginning at TS1Rh and progressing in the forward direction towards intermediate $\mathbf{2 R h}$. b) Plot of breaking $\mathrm{C}-\mathrm{H}$ bond distance $(\AA)$ versus trajectory steps beginning at TS1Rh and progressing in the forward direction towards intermediate $\mathbf{2} \mathbf{R h}$. Blue lines represent trajectories with long breaking $\mathrm{C}-\mathrm{H}$ distances and short forming $\mathrm{C}-\mathrm{H}$ distances and indicate progression beyond structure 2. Red lines represent recrossing trajectories that result in reformation of the ethyl group $\mathrm{C}-\mathrm{H}$ bond. In both plots the average trajectory step is $\sim 0.7 \mathrm{fs}$.

In addition to the $\beta$-hydrogen elimination and migratory insertion transition states for TS1Rh, we also calculated the $\mathrm{C}-\mathrm{C}$ bond rotation transition state for the methyl group. Consistent with Brookhart's NMR studies, ${ }^{4}$ the $\Delta G^{\ddagger}$ for C-C bond rotation is $5.4 \mathrm{kcal} / \mathrm{mol}$, which is essentially equivalent to the TS1Rh barrier height. We were unable to find an ethylene group rotation transition state for $\mathbf{1 R h}$. However, a rigid scan of ethylene group rotation suggests the barrier is $\sim 2 \mathrm{kcal} / \mathrm{mol}$ higher than TS1Rh. The closeness of energies of the $\beta$-hydrogen transfer, $\mathrm{C}-\mathrm{C}$ bond rotation, and ethylene group rotation are intriguing because we wondered if $\mathrm{C}-\mathrm{C}$ bond rotation and/or ethylene group rotation might be dynamically coupled with $\beta$-hydrogen transfer.

We also calculated the structures and energies for $\beta$-hydrogen transfer in 1Co. Similar to Hall's ab initio results, ${ }^{2}$ we found a concerted transition-state structure with motion corresponding to hydrogen transfer between two ethylene groups. The barrier for $\mathbf{2 C o}$ was found to be $\sim 2 \mathrm{kcal} / \mathrm{mol}$ higher than the Rh barrier, which is consistent with Brookhart's measurements of these barriers. ${ }^{4}$ We also explored the energy surface for $\mathbf{1} \mathbf{l}$. This reaction has a landscape profile similar to $\mathrm{Rh}$ with a two-step mechanism. However, in this case the $\mathbf{I r}-\mathrm{H}$ intermediate, $2 \mathbf{I r}$, is stabilized by $\sim 3 \mathrm{kcal} / \mathrm{mol}$ relative to TS1/r (see Figure 1d). 
A)

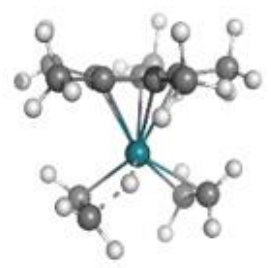

$1 \mathrm{fs}$

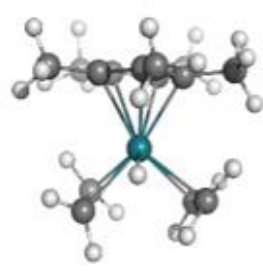

$20 \mathrm{fs}$

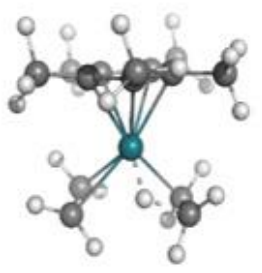

$54 \mathrm{fs}$

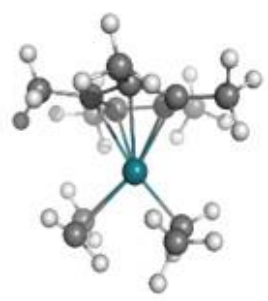

86 fs
B)

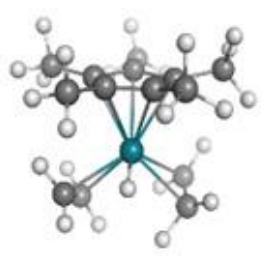

$231 \mathrm{fs}$

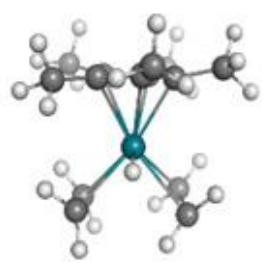

$443 \mathrm{fs}$

C)

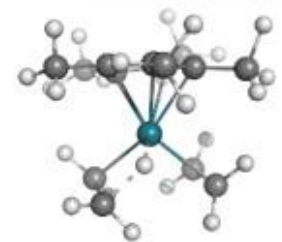

$1 \mathrm{fs}$

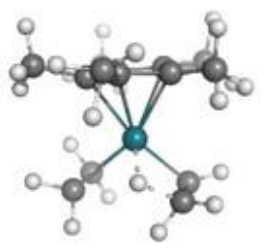

$176 \mathrm{fs}$

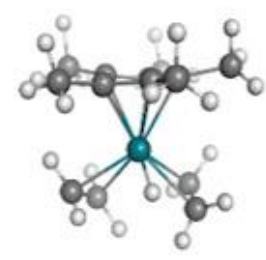

$261 \mathrm{fs}$

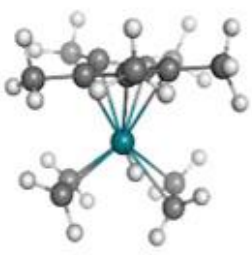

475 fs

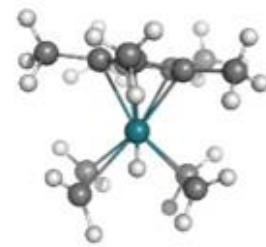

$21 \mathrm{fs}$

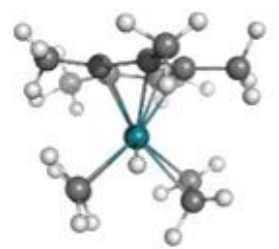

$225 \mathrm{fs}$

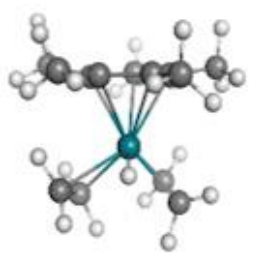

285 fs

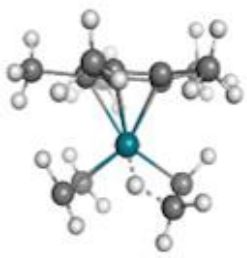

$528 \mathrm{fs}$

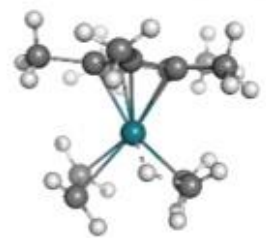

$34 \mathrm{fs}$

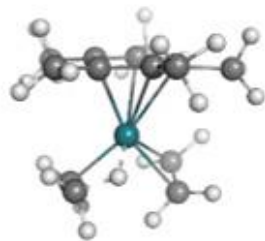

$244 \mathrm{fs}$

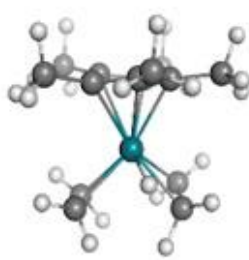

$415 \mathrm{fs}$

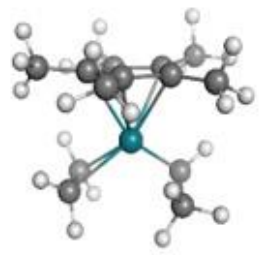

$542 \mathrm{fs}$

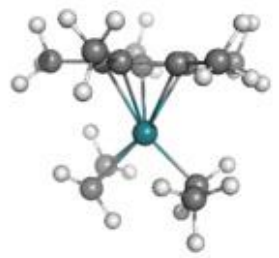

$80 \mathrm{fs}$

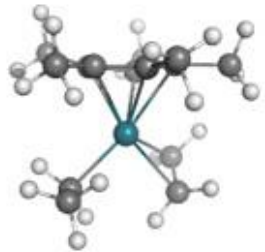

$291 \mathrm{fs}$

Figure 3. a) 3D time snapshots of a representative dynamically ballistic Rh trajectory initiated at TS1Rh that rapidly skipps the Rh-H intermediate. b) 3D time snapshots of a representative dynamically unrelaxed Rh trajectory initiated at TS1Rh where skipping occurs after a sampling of the Rh-H intermediate. c) 3D time snapshots of a representative back-and-forth trajectory where the hydrogen transferred between the ethyl group and ethylene occurs and then the reverse transfer occurs.

\section{Quasiclassical trajectories for [Cp*Rh"'(Et)(ethylene) $]^{+}$}


To examine the possibility of dynamical skipping of the $\mathrm{Rh}-\mathrm{H}$ intermediate, we initiated and propagated 85 forward and reverse connected reactive direct dynamics quasiclassical trajectories starting from TS1Rh. Figure 2a plots the forward direction steps of these M06/6-31G**[LANL2DZ] trajectories versus the distance of the forming $\mathrm{C}-\mathrm{H}$ bond that occurs upon complete $\beta$-hydrogen transfer. Figure $2 \mathrm{~b}$ plots the trajectory steps versus the breaking $\mathrm{C}-\mathrm{H}$ bond length. These plots show 45 blue trajectory lines that represent trajectories that skipped the $\mathrm{Rh}-\mathrm{H}$ intermediate $\mathbf{2} \mathbf{R h}$ and progressed beyond the second transition state resulting in complete $\beta$-hydrogen transfer. ${ }^{9,20}$ No trajectories over the course of $1500 \mathrm{fs}$ ended with the formation of the Rh-H intermediate. The 40 other trajectories, while initially progressed towards $\mathbf{2}$ from TS1Rh returned to and recrossed this transition state. These recrossing trajectories are marked as red lines in Figures $2 \mathrm{a}$ and $2 \mathrm{~b}$. This large amount of recrossing is perhaps not surprising given the flat potential energy surface where small forces can induce significant atomic motion.

Analysis of both the forming $\mathrm{C}-\mathrm{H}$ distances and the breaking $\mathrm{C}-\mathrm{H}$ bond distances reveals that there are generally two types of trajectories that skip the $\mathrm{Rh}-\mathrm{H}$ intermediate. There are 13 trajectories that bypass intermediate $\mathbf{2} \mathbf{R h}$ within approximately $75 \mathrm{fs}$, which are be considered ballistic trajectories because there is very little, if any, $\mathrm{Rh}-\mathrm{H}$ bond oscillations before proceeding to complete $\beta$-hydrogen transfer. Figure 3a shows time snapshots of one of the 13 ballistic trajectories. In this trajectory the $\mathrm{C}-\mathrm{H}$ bond is completely broken by $20 \mathrm{fs}$ and completely transferred to the ethylene group by $86 \mathrm{fs}$.

In addition to very fast skipping, there are 32 trajectories that that skip the $\mathrm{Rh}-\mathrm{H}$ intermediate between 100-1500 fs. We have labelled these trajectories as dynamically unrelaxed dynamical because they sample the Rh-H structure region, but do not fully undergo IVR to remain at this intermediate. Consistent with this idea, initiation of trajectories at intermediate $\mathbf{2} \mathbf{R h}$ resulted in all trajectories traversing TS1Rh and never remain at the $\mathrm{Rh}-\mathrm{H}$ intermediate. This indicates that the shallow well of $\mathbf{2} \mathbf{R h}$ on the potential energy surface is just not deep enough to result in any IVR of the Rh-H intermediate. Indeed, on the enthalpy and Gibbs energy surfaces TS1Rh and $\mathbf{2 R h}$ are essentially identical in energy and this surface is flat with no well.

To quantify the amount of sampling of the $\mathrm{Rh}-\mathrm{H}$ region in ballistic and unrelaxed trajectories, we tabulated the amount of Rh-H bond oscillations between the beginning and end of each forward trajectory. An oscillation is defined as complete movement of stretching and contraction motion of the $\mathrm{Rh}-\mathrm{H}$ distance. Figure 4a plots the amount of Rh-H oscillations for the 45 skipping trajectories. For the 13 ballistic trajectories they all have four or less oscillations before complete $\beta$-hydrogen transfer. The unrelaxed trajectories have between 6-68 oscillations. 

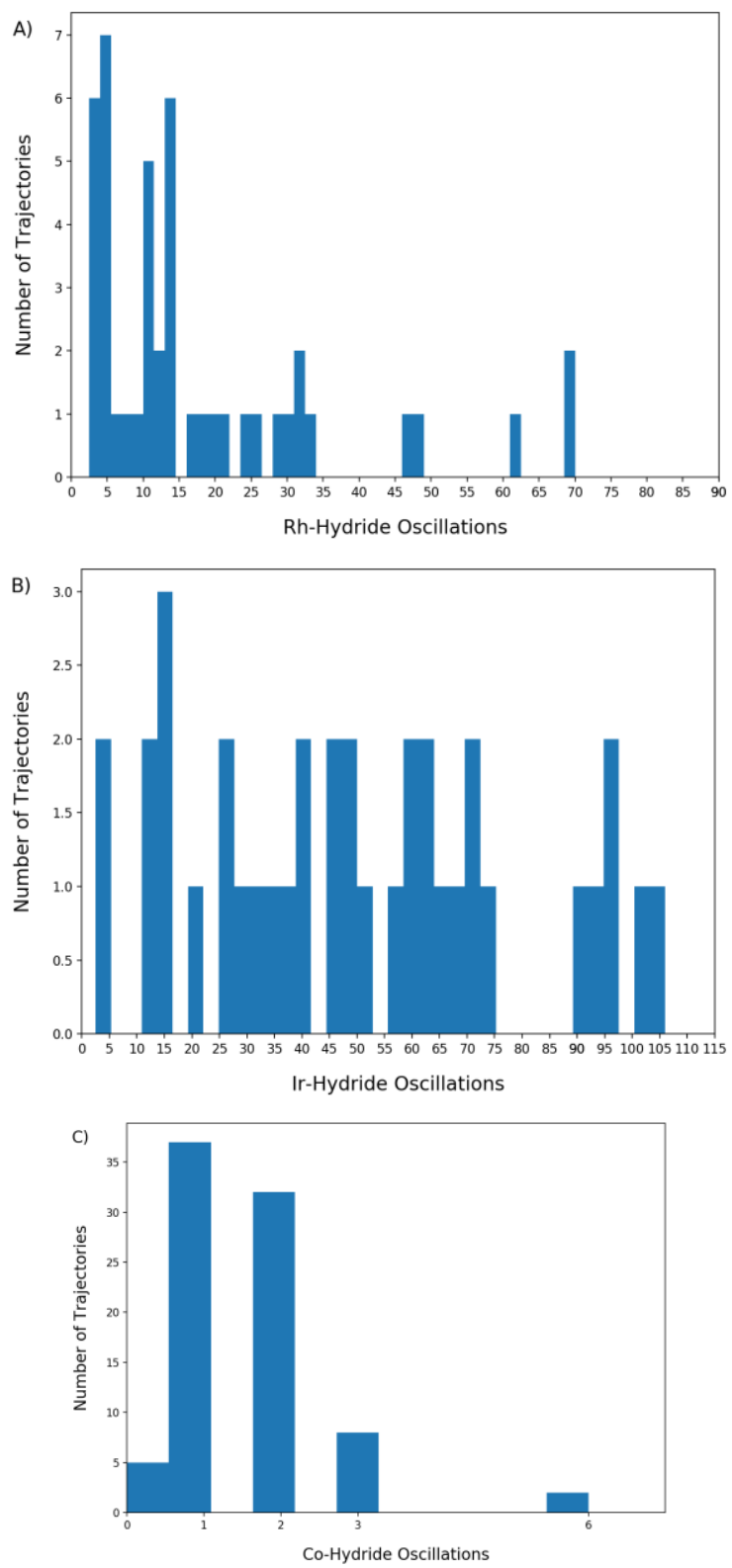

Figure 4. Number of trajectories with $\mathrm{M}-\mathrm{H}$ oscillations that occur from the transition state until formation of the new $\mathrm{C}-\mathrm{H}$ bond during $\beta$-hydrogen transfer for a) Rh skipping trajectories, b) Ir skipping trajectories, and c) all Co trajectories. Each $\mathrm{M}-\mathrm{H}$ oscillation was evaluated by counting the total number of complete oscillations before the bond was broken.

As a subset of the skipping trajectories, we identified a trajectory where after complete $\beta$ hydrogen transfer there was then complete reversal of hydrogen transfer. Figure $3 c$ shows time snapshots of this back-and-forth skipping trajectory. Between 1-80 fs there is full $\beta$-hydrogen transfer, but then starting at $176 \mathrm{fs}$ the newly formed $\mathrm{C}-\mathrm{H}$ bond is broken and the hydrogen is transferred in the reverse direction with completion of this process in just under $300 \mathrm{fs}$. While there was only one of these $\mathrm{Rh}$ trajectories with back-and-forth hydrogen movement, this type of mechanism is significantly more common in the Co and Ir reactions.

Inspection of Figure $2 \mathrm{~b}$ also shows that for the skipping trajectories mapped with blue lines, after complete cleavage of the $\mathrm{C}-\mathrm{H}$ bond there is formation of roughly two bands of structures. There is 
the upper band of structures with longer $\mathrm{C}-\mathrm{H}$ distances of $\sim 4 \AA$ and a lower band with distances of $<3 \AA$. From the transition state until about $250 \mathrm{fs}$ nearly all the skipping trajectories have shorter $\mathrm{C}$-H distances in Figure $2 \mathrm{~b}$. This relatively short $\mathrm{C}-\mathrm{H}$ distance corresponds to the structure where the transferred hydrogen remains with a direct agostic interaction at the Rh metal center. After $250 \mathrm{fs}$, many of the blue trajectories then have an increase in the $\mathrm{C}-\mathrm{H}$ distance and at later times there is some crossover between the upper and lower band. The upper blue band corresponds to a $\mathrm{C}-\mathrm{H}$ distance indicating that the transferred hydrogen is no longer engaged with the $\mathrm{Rh}$ metal centre, which requires $\mathrm{C}-\mathrm{C}$ bond rotation of the methyl group.

Figure 5 replots the forming and breaking $\mathrm{C}-\mathrm{H}$ bond distances similar to Figure 2, except the recrossing trajectories have been removed. This enhanced view of the trajectories shows the blue band where the transferred hydrogen remains directly interacting with the Rh metal centre while the yellow trajectories, which are a subset of the blue trajectories in Figure 2, show the hydrogen moving out of the agostic interaction with the Rh metal centre. Figure 5c shows 3D snapshots of this process for a representative trajectory. At $406 \mathrm{fs}$ after the transition state the hydrogen (colored yellow) has been fully transferred. Then at $527 \mathrm{fs}$ the $\mathrm{C}-\mathrm{C}$ bond rotation can be seen with the yellow hydrogen moving away from the Rh metal center and after several hundred more fs the hydrogen can be seen to sample the third possible conformational position of the ethyl group. Because Figure $5 a$ and $5 b$ show methyl group rotation after several hundred fs of $\beta$-hydrogen transfer this indicates that these two processes are not dynamically matched, and the $\mathrm{C}-\mathrm{C}$ bond rotation is a slightly slower process that is consistent with a nearly equal energy barrier to $\beta$-hydrogen transfer. While not dynamically matched to have a concerted $\beta$-hydrogen transfer and $\mathrm{C}$ - $\mathrm{C}$ bond rotation steps, it is clear that surmounting the $\beta$-hydrogen transfer transition state results in vibrationally unrelaxed intermediate that can rotate which $\mathrm{C}-\mathrm{H}$ bond is engaged with the Rh metal centre in an agostic interaction. We found 30 of the 45 skipping trajectories result in subsequent methyl group rotation. We also looked for ethylene group rotation. However, in accord with this process having a larger barrier than $\beta$-hydrogen transfer and C-C bond rotation we only identified two of the 45 trajectories that showed $180^{\circ}$ rotation of the ethylene group.

As shown in Scheme 1c, the energy landscape for the $\beta$-hydrogen transfer of $\left[\mathrm{Cp}^{*} \mathrm{Co}^{\prime \prime \prime}(\mathrm{Et}) \text { (ethylene) }\right]^{+}, \mathbf{1} \mathrm{Co}$, occurs through a single, concerted transition-state structure $\mathbf{2} \mathrm{Co}$. From a structural perspective, $\mathbf{2} \mathrm{Co}$, with a relatively advanced $\mathrm{Co}-\mathrm{H}$ interaction, looks very similar to the $\mathrm{Rh}-\mathrm{H}$ intermediate $\mathbf{2 R h}$. $\mathbf{2 C o}$ has a Co-H bond with a length of $1.5 \AA$, which is $0.1 \AA$ less than the $\mathrm{Rh}-\mathrm{H}$ bond in 2Rh.

Because of the significant $\mathrm{Co}-\mathrm{H}$ interaction, we wondered if trajectories emanating from the transition state $\mathbf{2 C o}$ would have $\mathrm{Co}-\mathrm{H}$ vibrational oscillations or be either dynamically ballistic or dynamically unrelaxed with several $\mathrm{Co}-\mathrm{H}$ vibrations. Similar to Figure 2, Figure 5 a plots the $\mathbf{2 C o}$ trajectory steps versus the distance of the forming $\mathrm{C}-\mathrm{H}$ bond and Figure $5 \mathrm{~b}$ plots the trajectory steps versus the breaking $\mathrm{C}-\mathrm{H}$ bond distance. These plots show that for all 84 trajectories complete $\beta$ hydrogen transfer occurs within $50 \mathrm{fs}$ after the transition state. This establishes a time frame for a concerted $\beta$-hydrogen transfer reaction mechanism. This timing is faster than the ballistic $\mathrm{Rh}$ trajectories, and so there is a dynamical distinction between concerted and dynamically ballistic type mechanisms.

As another means to compare the Co and Rh trajectories, we quantified the number of $\mathrm{Co}-\mathrm{H}$ oscillations that occur in the 84 Co trajectories. It is important to note that despite the imaginary frequency reaction coordinate motion of $\mathbf{2}$ Co being dominated by $\mathrm{C}-\mathrm{H}$ bond cleavage and formation, the $\mathrm{Co}-\mathrm{H}$ interaction is significant and it not necessarily obvious from the IRC that there are $2-3 \mathrm{Co}-\mathrm{H}$ oscillations that occur as hydrogen transfer completes. Figure $4 \mathrm{c}$ shows that $>35$ out of 84 trajectories have 2 complete $\mathrm{Co}-\mathrm{H}$ oscillations and $>30$ out of 84 trajectories have 3 complete $\mathrm{Co}-\mathrm{H}$ oscillations. Only a very few trajectories have 6 complete oscillations. 
Similar to the Rh trajectories, in addition to concerted one-step $\beta$-hydrogen transfer, the Co trajectories also showed several back-and-forth trajectories. This is indicated in Figure 5 a where the blue lines initially go to a short, fully formed $\mathrm{C}-\mathrm{H}$ bond length, but then revert and increase to a distance larger than $3 \AA \AA$. This occurred in nearly $10 \%$ of all trajectories. Additionally, there were several trajectories that showed multiple complete back-and-forth $\beta$-hydrogen transfers.

Again, similar to Rh, Figure $5 \mathrm{~b}$ also shows the dynamical $\mathrm{C}-\mathrm{C}$ bond rotation motion that occurs soon after $\beta$-hydrogen transfer is complete. The two upper bands in Figure $5 b$ show trajectories where the transferred hydrogen remains interacting with the Co metal centre and where the hydrogen disengages due to $\mathrm{C}-\mathrm{C}$ bond rotation and results in a longer $\mathrm{C}-\mathrm{H}$ distance. Different from $\mathrm{Rh}$ trajectories, for $\mathrm{Co}$, the majority of trajectories show that after $\sim 2000 \mathrm{fs}$ the transferred hydrogen remains in agostic interaction with Co. Observation that most of the Co trajectories have the hydrogen that was transferred remain in an agostic interaction is consistent with the higher barrier for $\mathrm{C}-\mathrm{C}$ bond rotation in $\mathbf{1 C o}$ compared to $\mathbf{1 R h}$. 

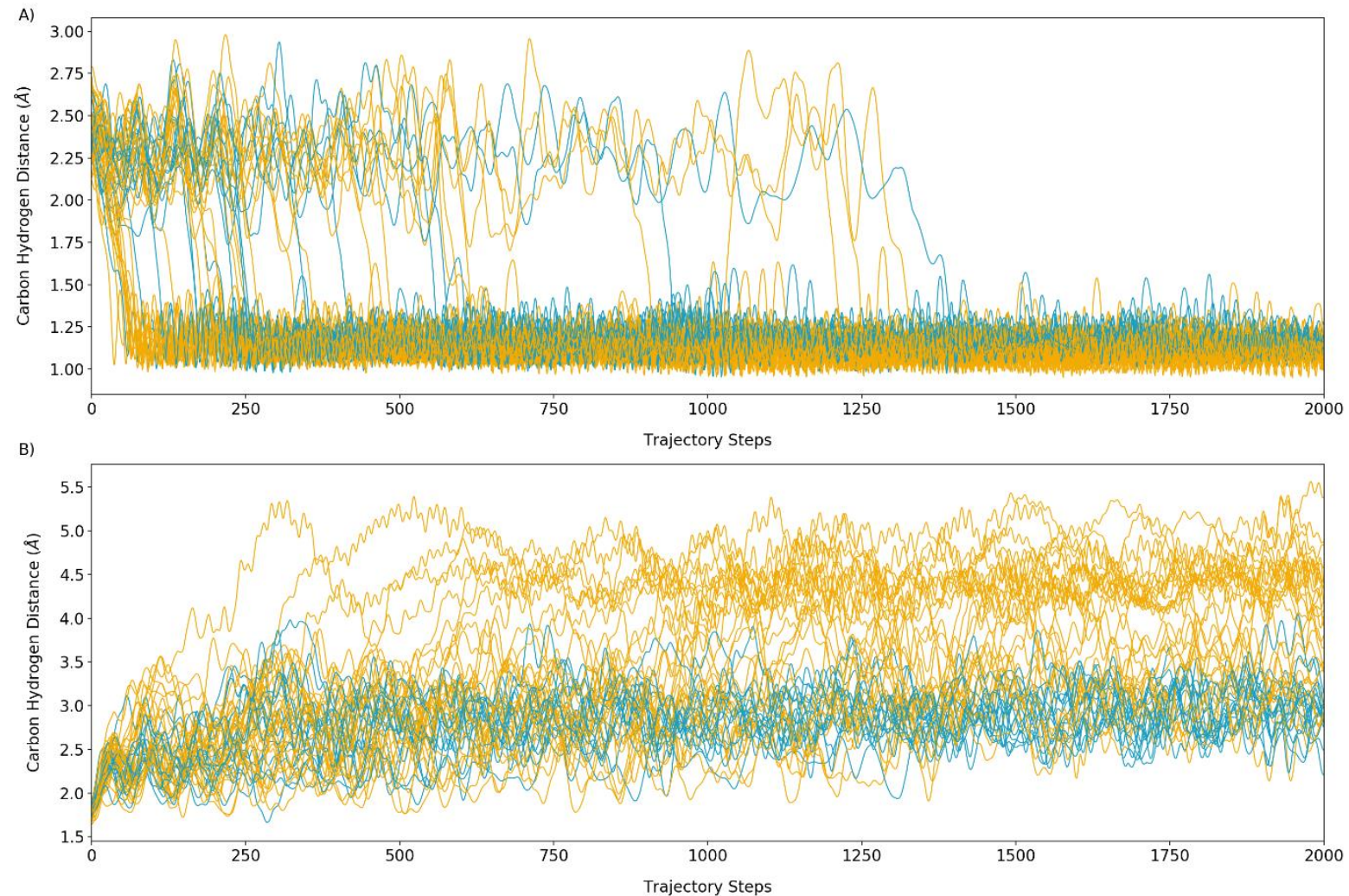

C)

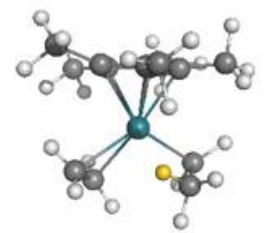

$406 \mathrm{fs}$

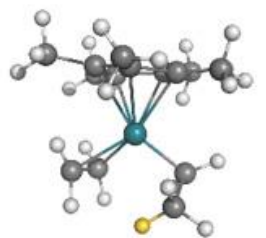

$1066 \mathrm{fs}$

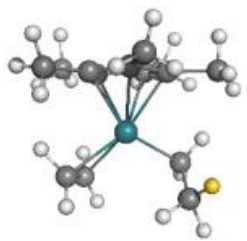

$527 \mathrm{fs}$

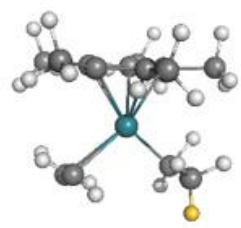

$1248 \mathrm{fs}$

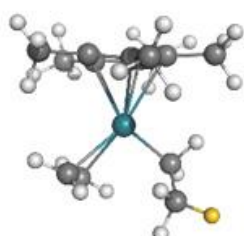

$684 \mathrm{fs}$

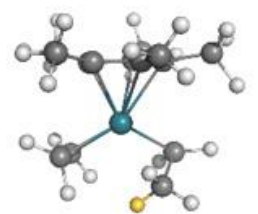

$1375 \mathrm{fs}$

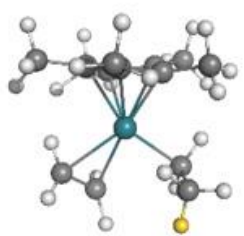

$942 \mathrm{fs}$

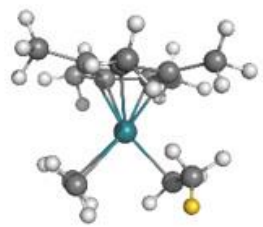

$1994 \mathrm{fs}$

Figure 5. a) For dynamically ballistic and unrelaxed trajectories, plot of the forming C-H bond distance (Å) versus trajectory steps beginning at TS1Rh and progressing in the forward direction towards intermediate $\mathbf{2 R h}$. b) For dynamically ballistic and unrelaxed trajectories, plot of breaking C-H bond distance $(\AA)$ versus trajectory steps beginning at TS1Rh and progressing in the forward direction towards intermediate $\mathbf{2 R h}$. In both plots the average trajectory step is $\sim 0.7 \mathrm{fs}$. Yellow lines are trajectories where after $\beta$-hydrogen transfer there is $\mathrm{C}-\mathrm{C}$ bond rotation of the methyl group and the transferred hydrogen rotates out of the agostic interaction. Blue lines represent trajectories where after the transferred hydrogen is transferred it remains in an agostic interaction with Rh. c) 3D time snapshots of a representative Rh trajectory where $\mathrm{C}-\mathrm{C}$ bond rotation occurs after $\beta$-hydrogen transfer. 

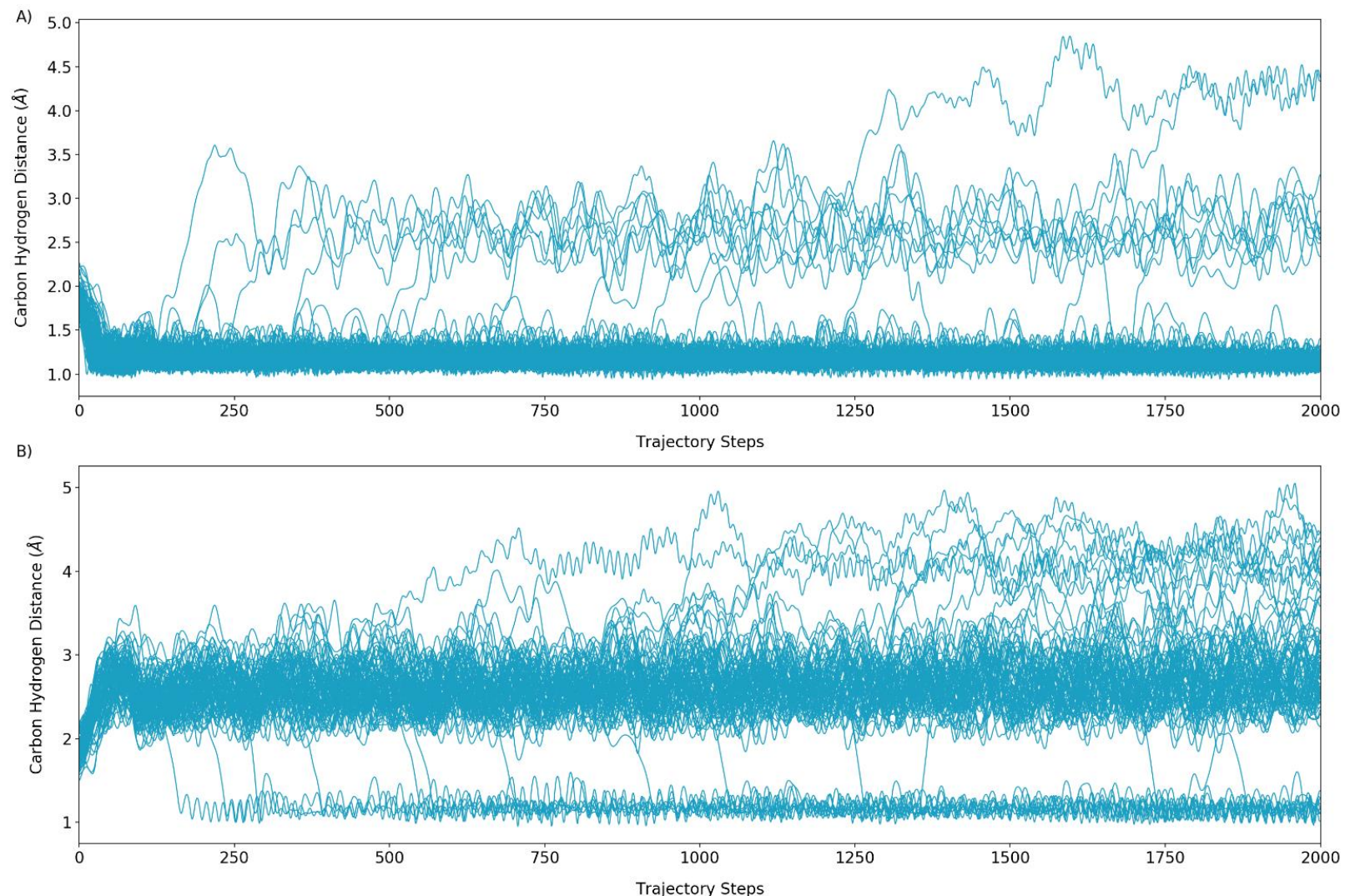

Figure 6. a) Plot of the forming $\mathrm{C}-\mathrm{H}$ bond distance $(\AA)$ versus trajectory steps beginning at $2 \mathrm{Co}$ and progressing in the forward direction. b) Plot of breaking $\mathrm{C}-\mathrm{H}$ bond distance $(\AA \AA)$ versus trajectory steps beginning at $2 \mathrm{Co}$ and progressing in the forward direction. Blue lines represent trajectories with long breaking $\mathrm{C}-\mathrm{H}$ distances and short forming $\mathrm{C}-\mathrm{H}$ distances. In both plots the average trajectory step is $\sim 0.7 \mathrm{fs}$. A total of 94 trajectories were propagated and 10 out of 94 resulted in recrossing. 

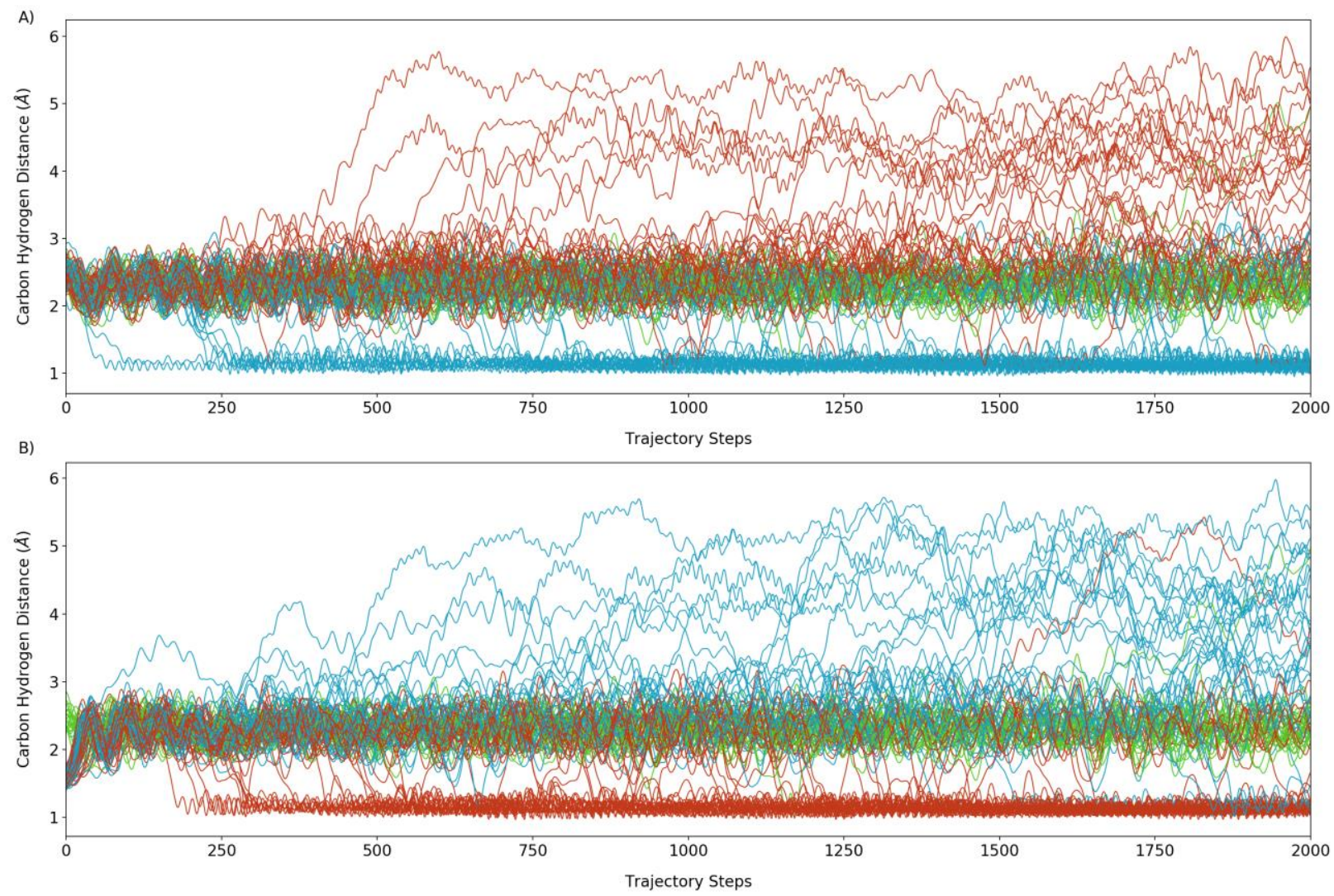

Figure 7. a) Plot of the forming C-H bond distance $(\AA)$ versus trajectory steps beginning at TS1Ir and progressing in the forward direction towards intermediate 2 Ir. b) Plot of breaking $\mathrm{C}-\mathrm{H}$ bond distance $(\AA)$ versus trajectory steps beginning at TS1Ir and progressing in the forward direction towards intermediate $\mathbf{2} \mathbf{R h}$. Blue lines represent trajectories with long breaking $\mathrm{C}-\mathrm{H}$ distances and short forming $\mathrm{C}-\mathrm{H}$ distances and indicate progression beyond structure $\mathbf{2 R h}$. Red lines represent recrossing trajectories that result in reformation of the ethyl group $\mathrm{C}-\mathrm{H}$ bond. Green lines represent trajectories that remain at the $\mathrm{Ir}-\mathrm{H}$ intermediate $2 \mathrm{Ir}$. In both plots the average trajectory step is $0.7 \mathrm{fs}$.

While there has not been an experimental report of the $\beta$-hydrogen transfer for $\left[\mathrm{Cp} * \mathrm{Ir}^{\prime \prime \prime}(\mathrm{Et}) \text { (ethylene) }\right]^{+}, \mathbf{1} \mathbf{I r}$, this analog of $\mathbf{1 R h}$ and $\mathbf{1 C o}$ is important to examine because the energy landscape is qualitatively different. Figure $1 \mathrm{c}$ shows that similar to $\mathbf{1 R h}, \mathbf{1} \mathbf{l r}$ has a two-step energy landscape for $\beta$-hydrogen transfer. However, different from $\mathbf{1 R h}$, the energy surface has a more stabilized Ir-H intermediate, which is $\sim 3 \mathrm{kcal} / \mathrm{mol}$ lower than TS1/r. This suggested to us the possibility that trajectories would stop at the Ir-H intermediate and undergo significant, if not complete, IVR.

We initiated and propagated 93 trajectories starting at TS1Ir. As we suspected, we indeed found trajectories that ended after $>2000 \mathrm{fs}$ at the $\mathrm{Ir}-\mathrm{H}$ intermediate 2 Ir. Figure 7a plots the forward direction trajectory steps versus the distance of the newly forming $\mathrm{C}-\mathrm{H}$ bond that occurs upon complete $\beta$ hydrogen transfer and Figure $7 \mathrm{~b}$ plots the trajectory steps versus the breaking $\mathrm{C}-\mathrm{H}$ bond length. In both of these plots the green lines show trajectories with intermediate $\mathrm{C}-\mathrm{H}$ bond lengths that correspond to intermediate $\mathbf{2}$ Ir. This occurred in 21 out of 93 trajectories.

Surprising to us, 36 out of 93 trajectories skipped the Ir-H intermediate. These skipping trajectories are shown as blue lines in Figures $7 \mathrm{a}$ and $7 \mathrm{~b} .36$ out of 93 were recrossing, which are plotted as red lines. These trajectories indicate that while the $1 / \mathrm{r}$ energy landscape has a two-step profile, there are both two-step and dynamically one-step mechanisms. In retrospect, it is perhaps not surprising that both two-step and one-step mechanisms were found with trajectories because the energy well for 2 Ir is 
only $3 \mathrm{kcal} / \mathrm{mol}$. Consistent with this understanding, Figures $7 \mathrm{a}$ and $7 \mathrm{~b}$ show that only two of the 36 skipping trajectories have ballistic mechanisms with skipping earlier than $250 \mathrm{fs}$. The other 34 skipping trajectories are best classified as dynamically unrelaxed mechanisms. This suggests that nearly all trajectories significantly sample the $\mathrm{Ir}-\mathrm{H}$ intermediate and skipping is dependent on the probability of IVR with the $3 \mathrm{kcal} / \mathrm{mol}$ well depth for $2 \mathrm{Ir}$. Also consistent with the label of dynamically unrelaxed, Figure $4 \mathrm{~b}$ shows that there are a nearly equal number of trajectories spread out between $10-100 \mathrm{Ir}-\mathrm{H}$ oscillations. To confirm the possibility that the lack of IVR accounts for skipping 2Ir, we launched trajectories at beginning at 2/r and found a similar ratio of trajectories that remained at this Ir-H intermediate versus progressing towards $\mathbf{1} \mathbf{I r}$ compared to what we found for trajectories initiated at TS1Ir.

\section{Conclusions}

The purpose of this work was to use direct dynamics DFT quasiclassical trajectories to understand the mechanistic continuum of $\beta$-hydrogen transfer for [Cp* $\mathrm{M}^{\prime \prime \prime}$ (Et)(ethylene)] $]^{+}$. Comparison of $\mathrm{M}=\mathrm{Rh}, \mathrm{Co}$, and Ir provided the ability to understand the relationship between the energy surface shape and the resulting dynamical mechanisms of this organometallic transformation.

For Rh, the static DFT energy landscape showed a two-step mechanism with a Rh-H intermediate, but quasiclassical trajectories commencing from the $\beta$-hydrogen elimination transition state revealed complete dynamical skipping of this intermediate. We found a dynamically ballistic mechanism with extremely fast skipping of the Rh-H intermediate and a dynamically unrelaxed mechanism where skipping occurred slower and is the result of incomplete IVR. Our trajectories also revealed the subsequent motion of $\mathrm{C}-\mathrm{C}$ bond rotation of the methyl group, which interchanges agostic interacting hydrogens.

For Co with a one-step, concerted energy landscape, trajectories showed extremely fast traversing of the transition-state zone ( $<50 \mathrm{fs}$ after the transition state). However, the majority of trajectories showed 2-3 complete $\mathrm{Co}-\mathrm{H}$ oscillations prior to full hydrogen transfer.

With a slightly more stabilized intermediate, Ir trajectories showed all possible mechanisms. Many trajectories ended at the Ir-H intermediate, indicating a two-step mechanism. However, there were more skipping trajectories, but the vast majority were dynamically unrelaxed with only a few ballistic trajectories, which is consistent with the more stabilized Ir-H intermediate compared to the Rh$\mathrm{H}$ intermediate.

The complete skipping of Rh-H and partial skipping of Ir-H intermediates demonstrates that for organometallic intermediates with a shallow well intermediate there is the possibility of dynamical mechanisms and caution should be used when interpreting and defining a mechanism based on the profiles of potential energy landscapes. In the case of $\beta$-hydrogen transfer, it is likely that the metalhydride needs to the stabilized by $>5 \mathrm{kcal} / \mathrm{mol}$ for a genuine two-step reaction mechanism to dominate if the intermediate is matched with the next transition state.

\section{Acknowledgments}

We thank Brigham Young University and the Office of Research Computing, especially the Fulton

Supercomputing Lab. R. C. thanks BYU Graduate Division for a HIDRA fellowship. We thank Matthew Teynor for assistance in analysis of metal-hydride oscillations and vibrational normal mode data.

\section{References}

1. P. Espinet,; A. C. Albéniz, 1,2-Insertion and $\beta$-Elimination. In Current Methods in Inorganic Chemistry, Volume 3, 2003, Chapter 6, 293-371.

2. Z. Lin, M. B Hall, M. F. Guest, J. Organomet. Chem. 1994, 478, 197-203.

3. S. Q.Niu, M. B. Hall, Chem. Rev. 2000, 100, 353-405. 
4. a) M. Brookhart, M. L. H. Green, R. B. A. Pardy, J. Chem. Soc., Chem. Commun. 1983, 691-693. b) G. F. Schmidt., M. Brookhart, J. Am. Chem. Soc. 1985, 107, 1443-1444. c) M. Brookhart, D. M. Lincoln, J. Am. Chem. Soc. 1988, 110, 8719-8720. d) M. Brookhart, D. M. Lincoln, A. F. Volpe Jr., G. F. Schmidt., Organometallics 1989, 8, 1212-1218. e) M. Brookhart, D. M. Lincoln, Bennett, M. A., S. Pelling, J. Am. Chem. Soc. 1990, 112, 2691-2694.

5. E. Fooladi, A. Krapp, O. Sekiguchi, M. Tilset, E. Uggerud, Dalton Trans. 2010, 39, 6317-6326.

6. H. Wadepohl, U. Kohl, M. Bittner, H. Köppel, Organometallics 2005, 24, 2097-2105.

7. M. Findlater, A. Cartwright-Sykes, P. S. White, C. K. Schauer, M. Brookhart, J. Am. Chem. Soc. 2011, 133, 12274-12284

8. R.Xu, G. Klatt, H. Wadepohl, H. Köppel, Inorg. Chem. 2010, 49, 3289-3296.

9. R. Carlsen, N. Wohlgemuth, L. Carlson, D. H. Ess, J. Am. Chem. Soc. 2018, 140, 11039-11045.

10. a) B. K. Carpenter, Chem. Rev. 2013, 113, 7265-7286. b) B. K. Carpenter, Angew. Chem. Int. Ed. Engl. 1999, 37, 3341-3350. c) R. Spezia, E. Martínez-Nuñez, S. Vazquez, W. L. Hase, Phil. Trans. R. Soc. A 2017, 375:20170035. d) U. Lourderaj, K. Park, W. L. Hase, Int. Rev. Phys. Chem. 2009, 113, 22362253. e) M. Paranjothy, R. Sun, Y. Zhuang, W. L. Hase, Wiley Interdisciplinary Reviews: Computational Molecular Science, 2013, 3, 296-316.

11. a) B. K. Carpenter, Annual Review of Physical Chemistry, 2005, 56, 57-89. b) B. K. Carpenter, Eds. Moss, R. A., Platz, M. S., Jones, M., Jr., Reactive Intermediate Chemistry, 2004, 925-960. c) J. Xie, W. L. Hase, Science 2016, 352, 32-33.

12. a) C. Doubleday, Applied Theoretical Organic Chemistry, Ed. D. J. Tantillo, b) S. R. Hare, D. J. Tantillo, Pure Appl. Chem. 2017, 89, 679-698.

13. a) T. Bekele, C. F. Christian, M. A. Lipton, D. A. Singleton, J. Am. Chem. Soc. 2005, 127, 9216-9223. b) Y. Oyola, D. A. Singleton, J. Am. Chem. Soc. 2009, 131, 3130-3131. c) D. A. Singleton, Singleton, D. A, J. Am. Chem. Soc. 2017, 139, 15710-15723. d) H. R. Aziz, D. A. Singleton, J. Am. Chem. Soc. 2017, 139, 5965-5972. e) B. Biswas, D. A. Singleton, J. Am. Chem. Soc. 2015, 137, 14244-14247. f) Z. Chen, Y. Nieves-Quinones, J. R. Waas, D. A. Singleton, J. Am. Chem. Soc. 2014, 136, 13122-13125. g) B. Biswas, S. C. Collins, D. A. Singleton, J. Am. Chem. Soc. 2014, 136, 3740-3743. h) X. S. Bogle, D. A. Singleton, Org. Lett. 2012, 14, 2528-2531. i) Z. Wang, J. S. Hirschi, D. A. Singleton, Angew. Chem. Int. Ed. Engl. 2009, 48, 9156-9159. j) H. Kurouchi, D. A. Singleton, Nat. Chem. 2018, 10, 237-241.

14. a) J. Xie, R. Otto, J. Mikosch, J. Zhang, J. Wester, W. L. Hase, Acc. Chem. Res. 2014, 47, 2960-2969. b) P. Manikandan, J. Zhang, W. L. Hase, J. Phys. Chem. A 2012, 116, 3061-3080. c) U. Lourderaj, K. Park, W. L. Hase, Int. Rev. Phys. Chem. 2008, 27, 361-403. d) J. G.Lopez, G. Vayner, U. Lourderaj, S. V. Addepalli, S. Kato, W. A. de Jong, T. L. Windus, W. L. Hase, J. Am. Chem. Soc. 2007, 129, 99769985. e) C. Doubleday, G. Li, Hase, W. L, Phys. Chem. Chem. Phys. 2002, 4, 304-312.

15. a) S. R. Hare, A. Li, D. J. Tantillo, Chem. Sci. 2018, 9, 8937-8945. b) R. P. Pemberton, D. J. Tantillo, Chem. Sci. 2014, 5, 3301-3308. c) Y. J. Hong, D. J. Tantillo, Nat. Chem. 2014, 6, 104-111. d) M. R. Siebert, P. Manikandan, R. Sun, D. J. Tantillo,, W. L. Hase, J. Chem. Theory Compu. 2012, 8, 12121222. e) M. R. Siebert, J. Zhang, S. V. Addepalli, D. J. Tantillo, W. L. Hase, J. Am. Chem. Soc. 2011, 133, 8335-8343.

16 a) C. Doubleday, C. P. Suhrada K. N. Houk, J. Am. Chem. Soc. 2006, 128, 90-94. b) C. Doubleday, M. Nendel, K. N. Houk, D. Thweatt, M. Page, J. Am. Chem. Soc. 1999, 121, 4720-4721. c) P. Yu, T. Q. Chen, Z. Yang, C. Q. He, A. Patel, Y.-h. Lam, C.-Y. Liu, K. N. Houk, J. Am. Chem. Soc. 2017, 139, 82518258. d) M. N. Grayson, Z. Yang, K. N. Houk, J. Am. Chem. Soc. 2017, 139, 7717-7720. e) X.-S. Xue, C. S. Jamieson, G-M. Borras, X. Dong, Z. Yang, K. N. Houk, J. Am. Chem. Soc. 2019, 141, 1217-1221.

17. Gaussian 16, Revision B.01, M. J. Frisch, G. W. Trucks, H. B. Schlegel, G. E. Scuseria, M. A. Robb, J. R. Cheeseman, G. Scalmani, V. Barone, G. A. Petersson, H. Nakatsuji, X. Li, M. Caricato, A. V. Marenich, J. Bloino, B. G. Janesko, R. Gomperts, B. Mennucci, H. P. Hratchian, J. V. Ortiz, A. F. Izmaylov, J. L. Sonnenberg, D. Williams-Young, F. Ding, F. Lipparini, F. Egidi, J. Goings, B. Peng, A. Petrone, T. 
Henderson, D. Ranasinghe, V. G. Zakrzewski, J. Gao, N. Rega, G. Zheng, W. Liang, M. Hada, M. Ehara, K. Toyota, R. Fukuda, J. Hasegawa, M. Ishida, T. Nakajima, Y. Honda, O. Kitao, H. Nakai, T. Vreven, K. Throssell, J. A. Jr. Montgomery, J. E. Peralta, F. Ogliaro, M. J. Bearpark, J. J. Heyd, E. N. Brothers, K. N. Kudin, V. N. Staroverov, T. A. Keith, R. Kobayashi, J. Normand, K. Raghavachari, A. P. Rendell, J. C. Burant, S. S. Iyengar, J. Tomasi, M. Cossi, J. M. Millam, M. Klene, C. Adamo, R. Cammi, J. W. Ochterski, R. L. Martin, K. Morokuma, O. Farkas, J. B. Foresman, D. J. Fox, Gaussian, Inc., Wallingford CT, 2016. 18. P. J. Hay, W. R. Wadt, J. Chem. Phys., 1985, 82, 270-283. b) P. J. Hay, W. R. Wadt, J. Chem. Phys. 1985, 82, 299-310.

19. R. Carlsen, J. R. Jenkins, D. H. Ess, Faraday Discussions, 2019, 220, 414-424.

20. a) C. N. Rowley, T. K. Woo, J. Am. Chem. Soc., 2008, 130, 7218-7219. b) C. N. Rowley, T. K. Woo, Organometallics, 2008, 27, 6405-6407. 